\title{
Cmambu
}

\section{КОМПОЗИЦИОННАЯ ТЕОРИЯ ЭМОЦИЙ: К ПОНИМАНИЮ МОРАЛЬНЫХ ЭМОЦИЙ И ЛЮБВИ}

\author{
Г.М. БРЕСЛАВ
}

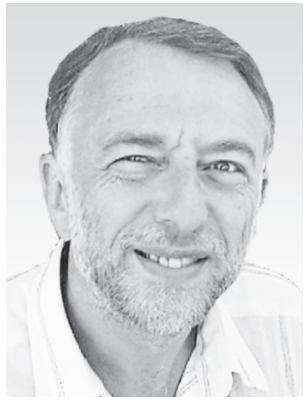

Бреслав Гершон Моисеевич - доцент Балтийской международной академии (Рига), доктор психологических наук, хабилитированный доктор Латвии.

Автор более 100 работ, в том числе монографий: «Эмоциональные особенности формирования личности в детстве: норма и отклонение» (1990), «Терпимы ли мы?» (2008, в соавт, на латышском), «Пол и образование» (1996, в соавт.), учебников «Психология эмоций» (2004, 2006, 2007), «Основы психологического исследования» (2010). Сфера научных интересов: психология эмоций, психология развития, история психологии, методы исследования личности, психометрика, социальная психология.

Контакты: g_bresl@latnet.lv

\begin{abstract}
Резюме
В современной психологии эмоций представляется актуальным не только сбор и анализ конкретных эмпирических данных, но и попытки их теоретического осмысления, которыми изобиловала психология XX в. Хотя ни одна из теорий не объясняет всего обилия накопленных фактов, это не означает, что их создание оказалось бесполезным для понимания богатства эмоциональной жизни человека. Одна из попыток интеграции этих теорий была представлена в композиционной теории эмоций (Бреслав, 1976, 1977а, 1984). В данной работе эта теория впервые используется для объяснения моральных эмоций стыда и вины, а также для понимания механизма становления и неустойчивости партнерской любви. Предложена схема основных элементов композиции стыда и вины, которая позволяет более ясно увидеть сходство и различие этих эмоций. В частности, к сходным элементам относятся наличие проступка в их предметном содержании и понимание его негативной оценки другими людьми. Однако если в случае стыда главным агентом стимуляции оказывается очевидец проступка, то в случае вины - жертва. Если в первом случае фокусом оценки является личность агента проступка, то во втором - сам проступок и его последствия для жертвы проступка. Если переживания стыда направляют человека, прежде всего, на защиту своего Я, то вина - на возмещение ущерба жертве. Проведенный композиционный анализ позволяет лучше понять условия позитивного и негативного развития чувства любви. Так, рассматривается встраивание этого чувства в наличную систему отношений, потребностей и привычек личности влюбленного. На определенном этапе оно может занимать центральное, доминирующее положение в иерархии отношений личности. Однако процесс этот чреват многочисленными нестыковками и конфликтами, которые могут препятствовать достижению любовью ведущего положения в иерархии отношений
\end{abstract}


личности. Неудача в этом процессе приводит к постепенному ослаблению этого чувства и трансформации валентности предмета любви. В свою очередь, сохранение этого чувства требует ежедневных усилий со стороны любящих.

Ключевые слова: композиционная теория эмоций, стыд, чувство вины, партнерская любовь, развитие любовных отношений.

Более 30 лет назад автором было предложено понимание эмоций, которое в известном смысле интегрировало классические теории и теории эмоций конца XX в. (Бреслав, 1976, 1977a, 1984). Более поздние модели эмоций Оутли и Джонсон-Лэрда, а также Кэрвера, Лоренса и Шайера прибавили лишь некоторые детали к пониманию механизма возникновения и действия эмоций (Carver et al., 1996; Oatley, Johnson-Laird, 1996). В обзоре теорий эмоций эти работы были ранее отнесены к группе эклектических моделей (Бреслав, 2004). В известном смысле любая интеграция взглядов разных ученых носит эклектический характер, что ни в коем случае не лишает ее эвристической ценности. Один из наиболее важных показателей продуктивности научной теории заключается в том, дает ли данная теория основу для понимания и дифференциации реальных явлений (Бреслав, 2010).

Главная мысль этой теории заключается в приписывании эмоциям функции обеспечения приоритетов как в познании, так и в поведении: «...Если познавательные процессы “отвечают" за "номенклатуру" образа, то эмоции обеспечивают его композицию» (Бреслав, 1977a, с. 7). Понятие композищии ориентирует как на предметное содержание эмоции, ее экспрессию, ее воздействие на поведение и состояние человека, так и на ее временну́ю, процессуальную составляющую. «Эмоции обеспечивают композиционное структурирование психического отражения и регулируют деятельность посредством выделения актуального (потенциального или реально достигнутого) на всех уровнях саморегуляции» (Бреслав, 1984, с. 19). «При таком понимании эмоции оказываются представленными в сознании лишь опосредствованно, через структуру (композицию) образа - в "рельефе” субъективного выделения предметного содержания. Фокус нашего сознания (“фигура” в восприятии) и представляет предмет эмоции» (Там же, с. 16).

Речь идет не только о структуре образа, на чем делали акцент сторонники и предшественники гештальтпсихологии, но и об организации всех психических и физиологических процессов в данный период времени, т.е. направлении процесса целеобразования, оценке текущих результатов достижения этих целей и т.д. вплоть до обеспечения фона этой активности (Бреслав, 1977б), что чаще всего обозначается как настроение. В состав элементов композиции эмоции входят и экспрессивная картина, и предмет эмоции (фокус оценки происходящего, произошедшего или предстоящего и направленность переживания), ее динамические характеристики (длительность и 
интенсивность), ее связь с актуальной ситуацией или социальным контекстом, как и ее позитивные и/или негативные последствия для организма и личности.

Эмоции при этом не ставятся на место мотивов, но именно они представляют мотивацию на уровне поведения и организма. Хотя мы феноменологически и объясняем свое поведение желанием получить удовольствие, нетрудно понять, что за этим удовольствием стоят вполне определенные мотивы и потребности. «Таким образом, критерии “эмоциональных оценок” или “эмоциональных санкций”, определяющих не только содержание психики, но и состояние организма, всегда задаются мотивационной сферой» (Бреслав, 1984, с. 15). Такие представления основаны на предшествующих подходах к пониманию функций эмоций психологов начала XX в. и второй половины XX в. (Asch, 1952; Bartlett, 1925; Duffy, 1941/1969; Frijda, 1970; Lewin, 1936; Вилюнас, 1976; Леонтьев, 1971).

В то же время необходимо четко дистанцироваться от крайностей эволюционных теорий базовых эмоций Томкинса, Изарда и Плачика (Tomkins, 1962; Izard, 1971; Plutchik, 1970), так же как и от их более современных версий (Oatley, JohnsonLaird, 1996), которые настаивают на обязательном поиске общих черт эмоциональной сферы человека и животных. При этом композиционная теория интегрирует идеи когнитивной теории эмоций, согласно которой порождение человеческих эмоций невозможно без когнитивных оценочных процессов (Lazarus et al., 1970; Schachter, Singer, 1962).
Особенно привлекательными выглядят попытки выделения основных компонентов эмоциональных процессов, что, однако, приводит к известным проблемам при акценте на анализе лишь базовых эмоций (Mesquita, 2001; Scherer, 1984, 1996). А это значит, что было бы ошибочным ставить знак равенства между эмоциональной сферой человека и животных, как это было ранее признано в психологии для интеллектуальной сферы. Это тем более очевидно в рамках социокультурного подхода, в основе которого лежит не только идея социального происхождения психических явлений, но и признание опосредствованного характера этих явлений (Breslav, 1994).

Позволяет ли композиционная теория лучше понять разнообразные данные современных исследований наиболее сложных моральных эмоций (Breslavs, 2013) или долговременных эмоциональных явлений, которые обычно относятся к группе чувств (Бреслав, 1984; Леонтьев, 1971)? В частности, помогает ли она ясно различать родственные эмоции стыда и вины по всему спектру их элементов? Позволяет ли она лучше понять противоречивость и удивительную уязвимость чувства любви, как и характер ее связи с другими чувствами и элементами личности?

\section{Моральные эмоции стыда и вины}

Для эмоции стыља характерна ясная экспрессивная картина покраснение лица, ушей и шеи, опускание головы, закрывание лица или глаз, отворачивание от возможных наблюдателей или предмета стыља, прекращение непосредственного 
контакта со свидетелями или предметом стыља. Переживание стыда носит зачастую столь болезненный характер (ощущение себя маленьким, ничтожным, грязным), что ведет к немедленным действиям по минимизации контакта с теми, кто осуждает или может осудить проступок (Cook, 1996). Это переживание может вызывать и другие эмоции и действия, направленные на минимизацию угрозы для Я-образа и самооценки, включая гнев и агрессию (Retzinger, 1991; Tangney et al., 1992). Дети иногда прячутся под стол или под кровать (если их стыдят дома), подростки убегают из дома, взрослые прекращают общение. Это свидетельствует о том, что именно социальные элементы ситуации приобретают отрицательную валентность, ибо влекут за собой угрозу Я-образу.

Чувство вины не имеет столь ясной экспрессии. В то же время исследователи указывают, что отягощенность виной может рассматриваться не только как метафора, но и как вполне конкретное переживание тяжести (Day, Bobocel, 2013; Izard, 1971; Tangney, Fischer, 1995). В частности, наличие тяжелого рюкзака на плечах приводит и к выраженному переживанию вины, и к избеганию действий, чреватых усилением этого переживания (Kouchaki et al., 2014). Смазанность или отсутствие специфической экспрессивной картины вины не исключает возможности выявления специфических нейрофизиологических процессов, сопровождающих переживания вины (Fourie et al., 2014). Тем самым можно выявить не только весьма специфичные паттерны поведения и переживания при возникновении таких эмоций, но и специфические паттерны реакции нашего организма, прежде всего ЦHC.

Хотя и стыд и вина связаны с конкретной ситуацией совершения проступка, связь эта весьма различна. В случае переживания стьда можно говорить об известной полезависимоcmu, т.е. в этом случае в сознании выделяется не столько проступок сам по себе, сколько очевидцы этого проступка или информированные о нем лица. Переживание проступка может быть совершенно другим в случае присутствия значимых или случайных людей. Не только для взрослых, но и для младших подростков при использовании структурированного интервью по гипотетическим ситуациям морального проступка или оплошности было обнаружено, что стыљ включает повышенную озабоченность тем, как другие люди могут оценивать субъекта проступка (Ferguson et al., 1991). Предметом стыда может быть и собственная фигура, что приводит к длительному, но дискретному состоянию стыда, приуроченному к соответствующим коммуникативным ситуациям, может стать чертой характера (Gilbert, Miles, 2002). В то же время трудно найти эмпирические подтверждения сохранения стыда на период, длительнее одногодвух месяцев (Andrews, 1998).

При появлении эмоции вины, связанной чаще всего с эмпатией, в сознании выделяется не столько очевидец, сколько жертва проступка. Мы склонны испытывать бо́льшую вину при нанесении ущерба тем, с кем находимся в кооперативных отношениях (Nelissen, 2014) или кто явственно обнаруживает на себе 
вредность нашего воздействия (Cryder et al., 2012). И в том и в другом случае актуализируется и более высокий уровень эмпатии, что также направляет внимание человека на возможности помощи жертве и компенсации ущерба. Именно акцент на действиях по компенсации нанесенного вреда отличает чувство вины от простого сопереживания, которое тоже может вести к просоциальным действиям. Однако в последнем случае человек сосредоточен лишь на актуальной ситуации страдания жертвы, а не на переоценке предшествующих действий, приведших к этим страданиям, как это происходит в случае вины. Предметное содержание и, соответственно, композиция проявления этих эмоций различаются при наличии общего содержания в познавательном поле (образ страдающего человека). В отличие от вины стыд скорее отрицательно связан с эмпатией (Tangney, 1995).

Понятно, что в каждом конкретном случае предметное содержание чувства вины будет отличаться своеобразием, ибо «...за одним и тем же “качеством" эмоции... может стоят практически бесконечное разнообразие предметных связей» (Бреслав, $1977 \mathrm{a}$, с. 4). Интенсивность и предметное содержание эмоции вины будет задаваться рядом существенных факторов: а) агент проступка (сам человек, его друг, родственник или представители его группы, нации и т.п.), б) тяжесть или последствия этого проступка (спортивная неудача, опоздание, «белая ложь», клевета, насилие и т.п.), в) степень необратимости этого проступка (возможность исправления содеянного), г) степень частности/общности и случайности/закономерности причины проступка (намеренный/ненамеренный проступок, вынужденный/инициативный проступок, частная неспособность или полное бессилие агента проступка) (Breslavs, 2013).

В случае своего намеренного и невынужденного проступка, приводящего к необратимым последствиям, чувство винь может становиться хроническим и дезадаптивным, направляющим сознание на отрицательный Я-образ. При этом может возникать генерализованное чувство вины на основе обобщенного обвинения себя, в то время как для обычного чувства вины такого рода переход на личность вовсе не является характерным (Parkinson, Illingworth, 2009). Более того, учитывая потенциальную большую длительность и глубину чувства вины, нетрудно понять, почему у пациентов с сильной депрессией обнаруживается связь этого состояния именно с виной, а не со стьљом (Alexander et al., 1999). В частности, родственники больных шизофренией проявляли виновную совесть (негативную оценку себя как морально неадекватных и самоосуждение), которая была положительно связана с их депрессией, страданием и неудачей в преодолении этих переживаний (Boye et al., 2002). Тем самым эти переживания вины, или угрызения совести, не только не помогали в этой жизненной ситуации, но и создавали порочный невротический круг.

Попробуем обобщить основные элементы композиции двух наиболее важных моральных эмоций стыда и вины (см. таблицу 1). Мы можем обнаружить их сходные элементы 
Таблица 1

Композиционные различия и сходство между эмоциями вины и стыда

\begin{tabular}{|c|c|c|}
\hline Элемент композиции & Стыд & Вина \\
\hline Фокус оценки & $\begin{array}{l}\text { «Я - плохой(ая)» - негативная } \\
\text { идентичность }\end{array}$ & $\begin{array}{l}\text { « сделал(а) это плохо» - } \\
\text { негативная оценка действия }\end{array}$ \\
\hline $\begin{array}{l}\text { Направленность } \\
\text { переживания }\end{array}$ & На себя и очевидцев & $\begin{array}{l}\text { На жертву и на исправление } \\
\text { нанесенного вреда }\end{array}$ \\
\hline Реакция & $\begin{array}{l}\text { Немедленная с выраженной экс- } \\
\text { прессией }\end{array}$ & $\begin{array}{l}\text { Отсроченная со сглаженной } \\
\text { экспрессией }\end{array}$ \\
\hline Длительность & Кратковременная & Долговременная \\
\hline $\begin{array}{l}\text { Связь с ситуацией } \\
\text { проступка }\end{array}$ & $\begin{array}{l}\text { Озабоченность мнением других } \\
\text { свидетелей по поводу проступка }\end{array}$ & $\begin{array}{l}\text { Озабоченность ущербом для } \\
\text { конкретных людей в связи с } \\
\text { проступком }\end{array}$ \\
\hline $\begin{array}{l}\text { Возможные } \\
\text { последствия }\end{array}$ & $\begin{array}{l}\text { Социальное признание «пра- } \\
\text { вильности» переживания, стрем- } \\
\text { ление улучшить свой имидж, } \\
\text { социальное избегание, социаль- } \\
\text { ная тревожность, враждебность } \\
\text { или агрессия }\end{array}$ & $\begin{array}{l}\text { Сближение, стремление к } \\
\text { исправлению ситуации, ком- } \\
\text { пенсация, депрессия, само- } \\
\text { уничижение }\end{array}$ \\
\hline
\end{tabular}

* Агентом проступка может быть и другой человек (или группа), с которым мы себя идентифицируем; причем проступком может быть и неоправданная пассивность.

(присутствие агента проступка, негативная оценка проступка и рефлексия негативной реакции других, желание сохранить свой имидж) и явные различия.

При четком различении стыља и вины обе эмоции оказываются негативно связаны с антисоциальным поведением (Menesini, Camodeca, 2008), что вполне соответствует взглядам Дж.М. Болдуина и 3. Фрейда о непосредственной связи этих эмоций с совестью. Но лишь чувство вины является фактором, позволяющим предсказывать просоциальное поведение в условиях школьного насилия (Olthof, 2012), т.е. позволяет ожидать сопротивление насилию и помощь жертве этого насилия. Подобные факты вполне соответствуют предшествующему различению композиций этих эмоций по характеристике возможных последствий.

При этом стыд также может вести к просоциальному поведению, хотя чаще всего в исследованиях речь идет лишь о дистанцировании себя от аморального поведения своей группы в случае стыда за свою группу (Gausel et al., 2012; Iyer et al., 2007). При стыде за себя человек ощущает себя тем, кем он не хотел бы быть в глазах других людей (LindsayHartz et al., 1995), а при стыде за 
свою группу он хочет отделить себя от такой группы (Piff et al., 2012).

Создание более дифференцированной картины стыда и вины на основе принципов композиционной теории позволяет ставить более точно нацеленные вопросы и проверять разные аспекты проявления этих эмоций. В частности, можно формулировать гипотезы не только по факту происхождения и проявления этих эмоций, но и по специфическому характеру последствий этих эмоций. Существенно более сложным является приложение этих принципов к пониманию чувств любви, ревности или ненависти, что связано с многоплановым и многоэтапным характером этих чувств. По мере своего становления чувство обрастает многочисленными производными формами, далеко не столь очевидными по своему выражению. Это особенно характерно для наиболее ценимого чувства в европейской культуре - любви, которое имеет столько же феноменологических ипостасей, сколько и любящих.

\section{Композиция любви}

Когда двухлетний ребенок говорит матери «любу», это, скорее всего, означает лишь боязнь разлуки, которая представлена у детей в самых разных культурах (Kagan et al., 1980). В то же время мать говорит ребенку о своей любви к нему, когда хочет его успокоить или стимулировать к терпению и самоограничению. Во втором случае у нас есть больше оснований считать такое вербальное выражение любви соответствующим реальному наличию этого чувства. При этом материнская любовь суще- ственно отличается от романтической (партнерской) любви не только явной асимметрией взаимоотношений, но и отсутствием сексуальной составляющей. Чаще всего появление чувства партнерской любви относят к подростковому возрасту и рассматривают как постепенную интеграцию привязанности, симпатий, заботы и сексуального репродуктивного поведения (Furman, Wehner, 1997).

C точки зрения композиционной теории, поведение влюбленных можно представить через метафору «магнитное поле» в духе топологической теории личности Курта Левина (Lewin, 1936). Именно в таком поле и развертывается последующая жизнедеятельность человека. У влюбленного начинают происходить существенные изменения в круге интересов и в Я-концепции, например, растут самооценка и самоэффективность (Aron et al., 1995). Предмет любви не только притягивает, но и меняет всю систему эмоциональных валентностей или векторов притяжения/отталкивания (в терминологии Левина) в предпочтениях человека. Прежние увлечения отходят на второй план, подчиняясь новой доминанте. При этом их новое место в значительной степени оказывается завязанным на приоритеты предмета любви. Если эти увлечения разделяются предметом любви, то они имеют возможность не только сохранить, но и усилить свою роль в жизни человека, если отвергаются, то их роль снижается, а их место занимают увлечения предмета любви. Благодаря идентификации с предметом любви, происходит воспроизведение черт поведения партнера и оказание помощи 
партнеру воспринимается как нечто полезное для себя (Aron et al., 1992).

Предмет любви, в силу своей положительной валентности и исключительного положения, пользуется максимальной эмоциональной поддержкой и терпимостью к недостаткам со стороны влюбленного (Swensen, Gilner, 1964), а также в некоторой степени идеализируется (Бреслав, 1987). Идеализация ведет к целому ряду проявлений самоосуществляющегося пророчества: взаимоотношения не разрушаются даже при сильных конфликтах и сомнениях; любящие выражают большую удовлетворенность взаимоотношениями; наконец, они приближаются к тому идеализированному образу, который был предложен их партнерами, т.е. начинают гораздо больше соответствовать оптимистическим ожиданиям своих партнеров (Murray et al., 1996). В этом смысле исследователи полагают, что возлюбленные могут существенно влиять на изменение личности партнера (Whitton et al., 1999). Оптимистические любящие оказываются более счастливыми в партнерских взаимоотношениях (Assad et al., 2007). Исследователи даже приходят к идее об идеаторной природе любви, ибо любящим во время работы или других занятий достаточно лишь представить предмет любви для улучшения настроения и появления комфортных переживаний любовных отношений (Poerio et al., 2015).

Однако, как известно, далеко не всегда становление этого чувства состоит из побед предмета любви над прошлым миром личности влюбленного. По мере своего становления чувство любви встраивается в уже существующую систему отношений и ценностей человека, и не всегда это встраивание происходит успешно, т.е. не всегда оно занимает ведущее место в иерархии взаимоотношений. Иногда позитивное развитие чувства прерывается достаточно быстро, натыкаясь на значительное сопротивление уже существующих чувств и ценностей. Торможение чувства любви, уже родившегося, но еще не достигшего центрального положения, происходит чаще всего в силу его несовместимости с некоторыми элементами этой личностной системы. Мать вскоре оказывается важнее возлюбленного, и теща (или свекровь) оказывается непреодолимым препятствием в создании устойчивых партнерских взаимоотношений. Эти несовместимые элементы представляют взаимоотношения любящего с другими людьми, но могут представлять и базовые потребности, интересы и даже привычки. Скорее всего, именно о последних говорил В. Маяковский: «Любовная лодка разбилась о быт».

Как известно в семейной психологии, несовместимость чувства любви с предшествующими родственными взаимоотношениями предмета любви не является неизбежной. Если любящий оказывается в ситуации жесткой альтернативы «или - или», то многочисленные личностно-ориентированные конфликты и размывание чувства любви, скорее всего, неизбежны. Однако композиция семейных взаимоотношений может складываться и по-другому. Вполне достижима не дизъюнктивная ситуация («или или»), а конъюнктивная (мы - одна семья). С родителями партнеров 
можно наладить взаимоотношения еще до вступления в брак. Часто для этого достаточно просто поинтересоваться их жизнью и предложить в чем-то свою помощь. В этом случае родители мужа или жены превращаются из потенциального препятствия в позитивный фактор развития взаимоотношений.

Изучение романтической или партнерской любви, с точки зрения композиционной теории, требует как понимания всего комплекса ожиданий и потребностей, связанных с предметом любви, так и понимания социального контекста и динамики этого чувства. Скорее всего, наиболее существенная перестройка всей мотивационной сферы может происходить лишь на пике этого чувства, когда предмет любви оказывается наиболее устойчивым фокусом сознания и переживаний. Однако этот пик, т.е. ведущее положение предмета любви в структуре взаимоотношений личности, может быть и не достигнут, ибо чувство может быть подавлено со стороны текущих негативных эмоций, возникающих как в рамках партнерских взаимоотношений, так и вне их.

Согласно композиционной теории, и возникновение, и последующая динамика чувства любви зависит от обобщения текущих эмоциональных явлений в процессе коммуникации с партнером или в мыслях о нем (Бреслав, 1984). Приятные акты взаимодействия в рамках партнерских взаимоотношений приводят к появлению и усилению позитивного чувства, но при ухудшении этого взаимодействия и преобладании негативных эмоций это чувство может быть заторможено. К сожале- нию, очень часто супружеские отношения, построенные на основе любви, складываются затем не лучшим образом. Долгоиграющие ежедневные конфликты постепенно меняют валентность предмета любви.

Например, плоховидящая женщина разлюбила своего мужа, который злоупотреблял выпивкой и не имел привычки класть вещи на место. Последнее обстоятельство чрезвычайно осложняло ей жизнь, особенно на кухне, где она до этого все делала вслепую, прекрасно зная, что где находится. Особенно много проблем стало возникать после рождения ребенка. Спорадические конфликты и негативные эмоции привели к тому, что недовольство (или векторы отталкивания, по Курту Левину) партнером стало перевешивать векторы притяжения. Сначала предмет любви приобрел амбивалентный характер, а затем валентность становилась все более низкой (близкой к 0) и скорее негативной. Психологам-консультантам хорошо известно, что в какой-то момент этот процесс становится необратимым, ибо проходит целый ряд стадий отторжения (Knapp, Vangelisti, 1992).

Лишь на последней стадии этого процесса распада взаимоотношений возможно и появление ненависти к бывшему предмету любви. Тем самым можно сказать, что популярный социальный стереотип «От любви до ненависти один шаг» не имеет психологических оснований (Breslavs, 1982). Это вовсе не значит, что любовь исключает ненависть. Наши данные говорят о том, что чувство любви скорее положительно 
связано с чувством ненависти (Breslavs, 2014). Однако предмет этих чувств различен. Любящий не терпит все то, что вредит его любимому человеку и его любовным взаимоотношениям. В то же время нельзя отрицать, что социальные стереотипы основаны на обобщении известного социального опыта, пусть это обобщение достаточно поверхностно. Основания для формирования такого стереотипа заключаются в типичной вербальной экспрессии конфликтов между возлюбленными. Нередко фраза «Я его (ее) терпеть не могу» или «Я его (ее) ненавижу» произносится в общении с родными и друзьями и воспринимается теми как выражение реального чувства, что на самом деле является лишь выражением обиды или недовольства действиями партнера. Чаще всего даже после полного распада партнерских взаимоотношений в ранней взрослости скорее ощущается не ненависть, а печаль (Robak, Weitzman, 1998).

В то же время развитие любви в рамках партнерских отношений может происходить и за счет обязательств, которые принимают на себя партнеры. Исследования возрастной динамики любви показывают, что именно эта составляющая любви в трехкомпонентной модели Р. Стернберга и некоторых других исследователей эмоций (интимность, страсть и обязательства) продолжает развиваться при переходе от старшего подросткового возраста к ранней и средней взрослости (Breslavs, 2009). При этом только первые две составляющие позволяют предсказывать удовлетворенность партнерскими взаимоотношениями (Cusack et al., 2012).
К. Расбалт предложил инвестиционную модель для объяснения причин принятия на себя обязательств по сохранению партнерских взаимоотношений (Rusbult, 1983). Согласно этой модели, одним из факторов принятия таких обязательств является воспринимаемое качество доступных альтернатив, куда входят не только альтернативы партнерских отношений, но и другие альтернативы, прямо или косвенно ослабляющие силы притяжения предмета любви. Другие факторы представлены степенью удовлетворенности взаимоотношениями и объемом вложений в развитие взаимоотношений. По мнению исследователей, все эти три фактора независимо друг от друга могут предсказывать принятие обязательств и прочность взаимоотношений (Rusbult, Buunk, 1993).

B то же время несомненна и возможность взаимодействия этих факторов. Наличие реальных и более привлекательных альтернатив может существенно снижать вклад партнеров в развитие взаимоотношений (Там же), так же как и удовлетворенность этими отношениями, ибо любые шероховатости при этом могут восприниматься болезненно. К тому же общение в Интернете создает иллюзию бесконечного числа альтернатив, что может препятствовать силам притяжения в реальных любовных отношениях и оказываться негативным фактором для стремления к сохранению взаимоотношений с предметом любви. В свою очередь, отсутствие такого стремления неизбежно приводит к редукции чувства любви независимо от созданного, как правило, задним числом, сценария (Sternberg et al., 2001). Правда, сама 
эта модель любви как рассказа-истории, предполагающая 25 разных сценариев, далеко не всегда разделяемых партнерами (Sternberg, 1994), вызывает серьезные сомнения.

Во-первых, многие представленные сценарии в работах Р. Стернберга и его коллег в значительной степени пересекаются (Бреслав, 2016). Во-вторых, чувство любви исходно вырастает из целого ряда различных потребностей и не может быть сведено лишь к одной из них или к одному представлению об идеальных или желаемых любовных взаимоотношениях. В-третьих, как вытекает из изложенных выше представлений, в процессе становления чувства любви происходит значительная трансформация личности влюбленного, что влечет за собой изменение мотивации самих любовных взаимоотношений. Мотивация знакомства, иногда весьма прагматическая, может значительно отличаться от последующих мотивов более зрелых взаимоотношений.

Популярный стереотип о редкости «настоящей любви» используется, как правило, также задним числом для объяснения причин распада любовных отношений. Чаще всего эталоном «настоящей любви» становятся литературные описания романтических отношений в романах Льва Толстого, Жорж Санд или Стендаля, которые по вполне понятным причинам имеют мало общего с реальными любовными взаимоотношениями как в XIX, так и в XX и XXI вв. Конечно, в XX в. ценность любви как основы выбора партнера и моногамного брака в европейской культуре резко возросла по сравнению с XIX в., когда выбор брачного партнера, как в странах Африки и Азии вплоть до сегодняшнего дня, преимущественно оставался за родителями.

Не менее далек от реальности и стереотип о самодостаточности любви. Согласно этому стереотипу, была бы любовь, а все остальное в партнерских взаимоотношениях сладится само собой. В то же время под этот стереотип была разработана модель самоподкрепления любви. В этой модели выделяется появление двойных обратных связей, когда повышенное внимание к предмету любви приводит к восприятию его сверхценности, которое, в свою очередь, усиливает это внимание (Tesser, Paulhus, 1976). Однако в этой модели отсутствует объяснение того, за счет чего образуются такие связи, и объяснение, за счет чего они исчезают, а также отсутствует понимание необходимости ежедневных усилий по сохранению и развитию любовных взаимоотношений.

Предмет любви не может долго оставаться в фокусе сознания без таких усилий, ибо многообразие взаимоотношений и потребностей порождает эмоции, направляющие человека совсем на другие объекты. Сохранить любовную доминанту нелегко и при совместной жизни, ибо взаимоотношения обрастают привычками, замещающими положительные эмоции, а сексуальные потребности ослабевают. Рождение детей также может быть негативным фактором любви к партнеру, ибо появляется новый предмет для такого чувства, особенно у женщины. Партнерская любовь, подобно культурному растению, нуждается в регулярной подпитке, для чего необходимы усилия обеих сторон. 
При всей идеализации возлюбленных любовные отношения вовсе не представляют улицу с односторонним движением даже в случае любви-наваждения (Felmlee, 1995), и у каждой стороны любовных взаимоотношений есть свои ожидания на получение соответствующей обратной связи. Каждая сторона ожидает, по крайней мере, что ее вклад в развитие взаимоотношений будет принят и по достоинству оценен. Если при этом партнеры еще верят в то, что этот вклад должен быть равноценным, то они ожидают от любимого человека не просто положительной оценки их вклада, но и не меньшего вклада со своей стороны. При наличии такой веры, те, кто воспринимает взаимные вклады как равноценные, более удовлетворены супружескими отношениями, чем те, кто считает эти вклады неравноценными (Buunk, Van Yperen, 1991).

Отсутствие подтверждения взаимных ожиданий партнеров чревато не только неудовлетворенностью отношениями и обилием отрицательных эмоций в этих отношениях, но и ослаблением чувства любви. Можно сказать, что «магнит» «размагничивается», т.е. предмет любви теряет свою способность притягивать с той же силой, ибо чувство любви является и психическим состоянием человека, и процессом. Оно или обогащается, или обедняется, но никак не консервируется в неизменном виде, подобно двигательным навыкам. Сохранение status quо для любви невозможно.

При отсутствии ожидаемой обратной связи постепенно (а иногда и достаточно быстро) все элементы композиции любви начинают редуци- роваться. Предмет любви уходит из фокуса сознания и минимизируется, мы уже не переживаем все происходящее с ним как свое собственное, не фантазируем о нем вне контакта, не реагируем так экспрессивно на его эмоции и действия, легко отключаемся от общения и не вспоминаем до встречи, уже не прощаем неадекватности поведения, не спешим с безусловной эмоциональной поддержкой.

Отсутствие подтверждения ожиданий партнеров проявляется и во взаимоотношениях предмета любви с третьими лицами. Как известно, чаще всего исследования указывают на положительную связь между любовью и ревностью или на отсутствие такой связи (Dugosh, 2000; Бреслав, 2008, 2013). При наличии любви ревность может служить фактором, предсказывающим удовлетворенность партнерскими взаимоотношениями (Dugosh, 2000). В случае неподтвержденных ожиданий и разочарования в предмете любви ревность может как полностью исчезать, так и приобретать неадекватный характер. Тем самым композиционная теория позволяет формулировать достаточно четкие гипотезы о взаимоотношениях любви, а также ее отдельных аспектов (интимности, страсти или обязательств) с другими чувствами и отношениями.

И в том и в другом случае это свидетельствует об изменении эмоциональной валентности предмета любви, причем если в первом случае речь может идти лишь о снижении положительной валентности, то во втором случае - о ее качественном изменении. К сожалению, если для изучения любви как состояния за последние полвека было разработано довольно много шкал, хороших с 
психометрической точки зрения (Hatfield, Sprecher, 1986; Hazan, Shaver, 1997; Hendrick, Hendrick, 1986; Rubin, 1970; Sternberg, 1997), то для изучения процессуальной характеристики любви пока таких методик нет.

Композиционная теория эмоций дает нам лишь общие ориентиры в понимании текущих эмоциональных явлений и чувств, оставляя за рамками анализа как весь круг когнитивных процессов, так и целый спектр психофизиологических явлений. Именно последние, в свою очередь, дают ответы на вопросы о возникновении многих пароксизмальных и психосоматических явлений в результате эмоциональных переживаний. Как известно, один и тот же стрессор, например безответная любовь, может закаливать одного человека и приводить к хроническому заболеванию у другого.

\section{Выводы}

Приложение идей композиционной теории к изучению моральных эмоций и любви позволяет лучше определить различие родственных эмоций стыда и вины и непостоянство и чрезвычайную вариативность проявления партнерской любви. Как и предполагалось, приложение этих идей к пониманию партнерской любви представляет большую трудность и ставит новые задачи перед исследователями, в частности, поиск точных инструментов изучения процессуальной характеристики любви.

Однако уже сейчас идеи композиционной теории позволяют отвергнуть модели процесса любви как реализацию какого-то одного сценария или сюжета (Sternberg, 1994; Sternberg et al., 2001) в силу как исходной полимотивации чувства любви, так и неизбежной трансформации структуры личности любящего в процессе выстраивания взаимоотношений с предметом любви. Композиционный анализ эмоций позволяет разрабатывать многоаспектные шкалы измерения эмоций стыда и вины.

\section{Литература}

Бреслав, Г. М. (1976). О роли эмоциональных явлений в трансформации предметного содержания деятельности. В кн.: А. Н. Леонтьев (Ред.), Новое в психологии (вып. 2, с. 42-48). М.: Изд-во Моск. ун-та.

Бреслав, Г. М. (1977а). Предметность эмоциональных явлений. Вестник Московского университета. Серия 14. Психология, 4, 3-11.

Бреслав, Г. М. (1977б). Система эмоциональной регуляции деятельности в процессе целеобразования. В кн. О. К. Тихомиров (Ред.), Психологические механизмы целеобразования (с. 95-109). М.: Наука.

Бреслав, Г. М. (1984). Эмоциональные процессы. Рига: Изд-во Латвийского гос. ун-та.

Бреслав, Г. (1987). Романтическая любовь и зрелая личность. Родник, 2, 63-66.

Бреслав, Г. М. (2004). Психология эмоций. М.: Смысл; Академия.

Бреслав, Г. (2008). Любовь и ревность: Друзья или враги? CommunicatoR, 1/2, 178-181. 
Бреслав, Г. М. (2010). Основы психологического исследования. М.: Смысл; Академия.

Бреслав, Г. (2013). Разработка частотного индекса сексуальной удовлетворенности (ЧИСУ) в диагностике супружеских отношений. Психология. Журнал высшей школы экономики, 10(1), $25-36$.

Бреслав, Г. М. (2016). Психология эмоций (4-е изд., переработанное). М.: Смысл.

Вилюнас, В. К. (1976). Психология эмоциональных явлений. М.: Изд-во Моск. ун-та.

Леонтьев, А. Н. (1971). Потребности, мотивы и эмоции. М.: Изд-во Моск. ун-та.

Alexander, B., Brewin, C. R., Vearnals, S., Wolff, G., \& Leff, J. (1999). An investigation of shame and guilt in a depressed sample. British Journal of Medical Psychology, 72, 323-338.

Andrews, B. (1998). Methodological and definitional issues in shame research. In P. Gilbert \& B. Andrews (Eds.), Shame: Interpersonal behavior, psychopathology, and culture (pp. 39-54). New York: Oxford University Press.

Aron, A., Aron, E. N., \& Smollan, D. (1992). Inclusion of other in the self scale and the structure of interpersonal closeness. Journal of Personality and Social Psychology, 63, 596-612.

Aron, A., Paris, M., \& Aron, E. (1995). Falling in love: prospective studies of self-concept change. Journal of Personality and Social Psychology, 69, 1102-1112.

Asch, S. (1962). Social psychology. Englewood Cliffs, NJ: Prentice-Hall.

Assad, K. K., Donnellan, M. B., \& Conger, R. D. (2007). Optimism: An enduring resource for romantic relationships. Journal of Personality and Social Psychology, 93(2), 285-297.

Bartlett, F. (1925). Feeling, imaging and thinking. British Journal of Psychology, 16(1), 16-28.

Boye, B., Bentsen, H., \& Malt, U. F. (2002). Does guilt proneness predict acute and long-term distress in relatives of patients with schizophrenia? Acta Psychiatrica Scandinavia, 106, 351-357.

Breslav, G. (1994, June-July). Vygotsky's concept of the "Social situation of development": Current perspective. Paper presented at the 13th Biennial Meetings of ISSBD, Amsterdam.

Breslavs, G. (1982). Cik soḷ no milestỉbas līdz naidam? Skola un G̣imene, 2.

Breslavs, G. (2009, August). Are adults' love and hate more advanced? The paper presented at the XIVth European Conference on Developmental Psychology, Vilnius.

Breslavs, G. (2013). Moral emotions, conscience and cognitive dissonance. Psychology in Russia: State of the Art, 6(4), 65-72. doi:10.11621/pir.2013.0405

Breslavs, G. (2014). Psychological security of two generations in Latvia.Journal of the Siberian Federal University. Humanities and Social Sciences, 7(12), 2191-2204.

Buunk, B. P., \& Van Yperen, N. W. (1991). Referential comparisons, relational comparisons and exchange orientation: their relation to marital satisfaction. Personality and Social Psychology Bulletin, 17, 710-718.

Carver, C. S., Lawrence, J. W., \& Scheier, M. F. (1996). A control-process perspective on the origins of affect. In L. L. Martin \& A. Tesser (Eds.), Striving and feeling: Interaction among goals, affect, and self-regulation (pp. 11-52). Mahwah, NJ: LEA Publishers.

Cook, D. R. (1996). Empirical studies of shame and guilt: The Internalized Shame Scale. In D. L. Nathanson (Ed.), Knowing feeling: Affect, script and psychotherapy (pp. 132-165). New York: Norton.

Cryder, C. E., Springer, S., \& Morewedge, C. K. (2012). Guilty feelings, targeted actions. Personality and Social Psychology Bulletin, 38, 607-618. doi:10.1177/0146167211435796

Cusack, C. E., Hughes, J. L., \& Cook, R. E. (2012). Components of love and relationship satisfaction: Lesbians and heterosexual women. Psi Chi Journal of Psychological Research, 17(4), 171-179.

Day, M. V., \& Bobocel, D. R. (2013). The weight of a guilty conscience: Subjective body weight as an embodiment of guilt. PLoS ONE, 8(7), 1-7. doi:10.1371/journal.pone.0069546 
Duffy, E. (1941/1969). An explanation of "emotional" phenomena without the use of the concept "emotion". In M. Arnold (Ed.), The nature of emotion (pp. 129-140). Harmondsworth: Penguin Books.

Dugosh, J. W. (2000). On predicting relationship satisfaction from jealousy: the moderating effects of love. Current Research in Social Psychology, 5(17), 254-263.

Felmlee, D. (1995). Fatal attractions: Affection and disaffection in intimate relationship. Journal of Social and Personal Relationships, 12, 295-311.

Ferguson, T. J., Stegge, H., \& Damhuis, I. (1991). Children understanding of guilt and shame. Child Development, 62, 827-839.

Fourie, M. M., Thomas, K. G. F., Amodio, D. M., Warton, C. M. R., \& Meintjes, E. M. (2014). Neural correlates of experienced moral emotion: An fMRI investigation of emotion in response to prejudice feedback. Social Neuroscience, 9(2), 203-218. doi:10.1080/17470919.2013.878750

Frijda, N. H. (1970). Emotion and recognition of emotion. In M. Arnold (Ed.), Feelings and emotions (pp. 241-250). New York: Academic Press.

Furman, W., \& Wehner, E.A. (1997). Adolescent romantic relationships: A developmental perspective. In S. Shulman \& A. Collins (Eds.), Romantic relationships in adolescence: New Directions for Child Development (pp. 21-36). San Francisco: Jossey-Bass.

Gausel, N., Leach, C. W., Vignoles, V. L., \& Brown, R. (2012). Defend or repair? Explaining responses to ingroup moral failure by disentangling feelings of shame, rejection, and inferiority. Journal of Personality and Social Psychology, 102, 941-960. Retrieved from http://dx.doi.org/10.1037/ a0027233

Gilbert, P. \& Miles, J. (Eds.). (2002). Body shame: Conceptualisation, research and treatment. Hove: Brunner-Routledge.

Hatfield, E., \& Sprecher, S. (1986). Measuring passionate love in intimate relations. Journal of Adolescence, 9, 383-410.

Hazan, C., \& Shaver, P. (1997). Romantic love conceptualised as an attachment process. In M. Hewstone, A. S. Manstead, \& Stroebe, W. (Eds.), The Blackwell reader in social psychology (pp. 377-406). Oxford: Blackwell.

Hendrick, C., \& Hendrick, S. (1986). A theory and method of Love. Journal of Personality and Social Psychology, 50, 392-402.

Iyer, A., Schmader, T., \& Lickel, B. (2007). Why individuals protest the perceived transgressions of their country: The role of anger, shame, and guilt. Personality and Social Psychology Bulletin, 33, 572-587. Retrieved from http://dx.doi.org/10.1177/0146167206297402

Izard, C. E. (1971). The face of emotion. New York: Appleton-Century-Crofts.

Kagan, J., Keasley, R. B., \& Zeiazo, P. R. (1980). Infancy: Its place in human development. Cambridge, MA: Harvard University Press.

Knapp, M. L., \& Vangelisti, A. (1992). Interpersonal communication and human relationships (2nd ed.). Boston: Allyn \& Bacon.

Kouchaki, M., Gino, F., \& Jami, A. (2014). The burden of guilt: Heavy backpacks, light snacks, and enhanced morality. Journal of Experimental Psychology: General, 143(1), 414-424. doi:10.1037/a0031769

Lazarus, R. S., Averill, J. R., \& Opton, E. M. (1970). Toward a cognitive theory of emotions. In M. Arnold (Ed.), Feelings and emotions (pp. 207-232). New York: Academic Press.

Lewin, K. (1936). Principles of topological psychology. New York: McGraw-Hill. 
Lindsay-Hartz, J., De Rivera, J., \& Mascolo, M. F. (1995). Differentiating guilt and shame and their effect on motivation. In J. P. Tangney \& K. Fisher (Eds.), Self-conscious emotions: The psychology of shame guilt, embarrassment, and pride (pp. 274-300). New York: Guilford Press.

Menesini, E., \& Camodeca, M. (2008). Shame and guilt as behaviour regulators: Relationships with bullying, victimization and prosocial behaviour. British Journal of Developmental Psychology, 26, 183-196.

Mesquita, B. (2001). Emotions in collectivist and individualist contexts. Journal of Personality and Social Psychology, 80(1), 68-74.

Murray, S. L., Holmes, J. G., \& Griffin, D. W. (1996). The benefits of positive illusions: Idealization and the construction of satisfaction in close relationships. Journal of Personality and Social Psychology, 70, 79-98.

Nelissen, R. M. A. (2014). Relational utility as a moderator of guilt in Social Interactions. Journal of Personality and Social Psychology, 106(2), 257-271. doi:10.1037/a0034711

Oatley, K., \& Johnson-Laird, P. N. (1996). The communicative theory of emotions: Empirical tests, mental models, and implications for social interaction. In L. L. Martin \& A. Tesser (Eds.), Striving and feeling: Interaction among goals, affect, and self-regulation (pp. 363-393). Mahwah, NJ: LEA Publishers.

Olthof, T. (2012). Anticipated feelings of guilt and shame as predictors of early adolescents' antisocial and prosocial interpersonal behaviour. European Journal of Developmental Psychology, 9(3), 371-88.

Parkinson, B., \& Illingworth, S. (2009). Guilt in response to blame from others. Cognition and Emotion, 23(8), 1589-1614.

Piff, P. K., Martinez, A. G., \& Keltner, D. (2012). Me against we: Ingroup transgression, collective shame, and ingroup directed hostility. Cognition and Emotion, 46, 634-649. Retrieved from http://dx.doi.org/10.1080/02699931.2011.595394.

Plutchik, R. (1970). Emotions, evolution, and adaptive processes. In M. Arnold (Ed.), Feelings and emotions (pp. 3-24). New York: Academic Press.

Poerio, G. L., Totterdell, P., Emerson, L.-M., \& Miles, E. (2015). Love is the triumph of the imagination: Daydreams about significant others are associated with increased happiness, love and connection. Consciousness and Cognition, 33, 135-144. doi:10.1016/j.concog.2014.12.011

Retzinger, S. M. (1991). Violent emotions: Shame and rage in marital quarrels. Newbury Park, CA: Sage.

Robak, R. W., \& Weitzman, S. P. (1998). The nature of grief: Loss of love relationships in young adulthood. Journal of Personal and Interpersonal Loss, 3(2), 205-216.

Rubin, Z. (1970). Measurement of romantic love. Journal of Personality and Social Psychology, 16, 265-273.

Rusbult, C. E. (1983). A longitudinal test of the investment model: The development (and deterioration) of satisfaction and commitment in heterosexual involvements. Journal of Personality and Social Psychology, 45, 101-117.

Rusbult, C. E. \& Buunk, A. P. (1993). Commitment processes in close relationships: an interdependence analysis. Journal of Social and Personal Relationships, 10, 175-204.

Schachter, S., \& Singer, J. E. (1962). Cognitive, social, and physiological determinants of emotional state. Psychological Review, 69, 379-399.

Scherer, K. R. (1984). On the nature and function of emotion: A component process approach. In K. R. Scherer \& P. Ekman (Eds.), Approaches to emotion (pp. 293-317). Hillsdale, NJ: Erlbaum.

Scherer, K. (1996). Emotion. In M. Hewstone, W. Stroebe, \& G. M. Stephenson (Eds.), Introduction to social psychology (pp. 279-315). Oxford: Blackwell Publ.

Sternberg, R. J. (1994). Love is a story. The General Psychologist, 30(1), 1-11. 
Sternberg, R. J. (1997). Construct validation of a triangular love scale. European Journal of Social Psychology, 27(3), 313-335.

Sternberg, R., Hojjat, M., \& Barnes, M. (2001). Empirical tests of aspects of a Theory of love as a story. European Journal of Personality, 15, 199-218.

Swensen, C., \& Gilner, F. (1964). Factor analysis of self-report statement on love relationships. Journal of Individual Psychology, 20, 186-188.

Tangney, J. P. (1995). Shame and guilt in interpersonal relationships. In J. P. Tangney \& K.W. Fischer (Eds.), Self-conscious emotions: Shame, guilt, embarrassment, and pride (pp. 114-139). New York: Guilford Press.

Tangney, J. P., \& Fisher, K. W. (Eds.). (1995). Self-conscious emotions: The psychology of shame guilt, embarrassment, and pride. New York: Guilford Press.

Tangney, J. P., Wagner, P., Fletcher, C., \& Gramzow, R. (1992). Shamed into anger? The relation of shame and guilt to anger and self-reported aggression. Journal of Personality and Social Psychology, 62, 669-675.

Tesser, A., \& Paulhus, D. L. (1976). Toward a causal model of love. Journal of Personality and Social Psychology, 34, 1095-1100.

Tomkins, S. S. (1962). Affect, imagery, and consciousness (Vol. 1: The positive affects). New York: Springer.

Whitton, S. W., Rusbult, C. E., \& Wieselquist, J. (1999). Close partner as sculptor of the ideal self: Behavioral affirmation and the Michelangelo phenomenon. Journal of Personality and Social Psychology, 77(2), 294-324.

\title{
Compositional Theory of Emotion: Understanding Moral Emotion and Love
}

\author{
Gershon Breslavs \\ Baltic International Academy, Dr. Habilitatis Psychology \\ E-mail: g_bresl@latnet.lv \\ Address: 4 Lomonosova str., Riga, LV-1003, Latvia
}

\begin{abstract}
It seems that in contemporary psychology of emotion not only data collection and their analysis is topical, but also theoretical interpretations of these facts that psychology in the 20th century was full of. Although no theory can explain all richness of collected facts in the field, it does not mean that the creation of these theories is useless for the understanding of human emotional life. One of the attempts to integrate these theories is represented in the compositional theory of emotion (Breslav, 1976, 1977a, 1984). In this article the theory was used for the first time for the understanding of moral emotions of shame and guilt, as well as the understanding of the mechanism of development and instability of partnership love. The design of the main compositional elements of shame and guilt was proposed, which allows see in a more precise way the
\end{abstract}


similarity and difference of shame and guilt. In particular, similar elements include the existence of transgression in the object-matter of these emotions and the understanding of the transgression's negative estimation by others. However, while with shame the main agent of stimulation is a beholder of the transgression, with guilt it is the victim. In the first case the locus of estimation is the personality of transgression's agent, in the second - the transgression and its consequences for the victim. While experiencing shame directs the person on defending him/herself, guilt - on the compensation of transgression's damage to the victim. The compositional theory of emotion also enables us to understand better the conditions of positive and negative development of love. In particular, this sentiment's inclusion in the existing system of needs, habits and relationships of the lover's personality is considered. At a certain stage love can become central, which means its dominant place in the hierarchy of the person's relationships. If this process fails, love will decrease gradually and the target of love's valence will be transformed. In its turn, the survival of love requires daily efforts from lovers.

Keywords: compositional theory of emotion, shame, guilt, partnership love, development of love relationships.

\section{References}

Alexander, B., Brewin, C. R., Vearnals, S., Wolff, G., \& Leff, J. (1999). An investigation of shame and guilt in a depressed sample. British Journal of Medical Psychology, 72, 323-338.

Andrews, B. (1998). Methodological and definitional issues in shame research. In P. Gilbert \& B. Andrews (Eds.), Shame: Interpersonal behavior, psychopathology, and culture (pp. 39-54). New York: Oxford University Press.

Aron, A., Aron, E. N., \& Smollan, D. (1992). Inclusion of other in the self scale and the structure of interpersonal closeness. Journal of Personality and Social Psychology, 63, 596-612.

Aron, A., Paris, M., \& Aron, E. (1995). Falling in love: prospective studies of self-concept change. Journal of Personality and Social Psychology, 69, 1102-1112.

Asch, S. (1962). Social psychology. Englewood Cliffs, NJ: Prentice-Hall.

Assad, K. K., Donnellan, M. B., \& Conger, R. D. (2007). Optimism: An enduring resource for romantic relationships. Journal of Personality and Social Psychology, 93(2), 285-297.

Bartlett, F. (1925). Feeling, imaging and thinking. British Journal of Psychology, 16(1), 16-28.

Boye, B., Bentsen, H., \& Malt, U. F. (2002). Does guilt proneness predict acute and long-term distress in relatives of patients with schizophrenia? Acta Psychiatrica Scandinavia, 106, 351-357.

Breslav, G. M. (1976). O roli emotsional'nykh yavlenii v transformatsii predmetnogo soderzhaniya deyatel'n ost $i$ [On the role of emotional phenomena in the transformation of objective content of activity]. In A. N. Leontiev (Ed.), Novoe v psikhologii [New in psychology] (Iss. 2, pp. 42-48). Moscow: Moscow University Press.

Breslav, G. M. (1977a). Predmetnost' emotsional'nykh yavlenii [The objectivity of the emotional phenomena]. Vestnik Moskozskogo Universiteta. Seriya 14. Psikhologiya, 4, 3-11.

Breslav, G. M. (1977b). Sistema emotsional'noi regulyatsii deyatel'nosti v protsesse tseleobrazovaniya [System of emotional regulation of activity in the process of goal formation]. In O. K. Tikhomirov (Ed.), Psikhologicheskie mekhanizmy tseleobrazovaniya [Psychological mechanisms of goal formation] (pp. 95-109). Moscow: Nauka. 
Breslav, G. M. (1984). Emotsional'nye protsessy [Emotional processes]. Riga: University of Latvia.

Breslav, G. (1987). Romanticheskaya lyubov' i zrelaya lichnost' [Romantic love and mature personality]. Rodnik, 2, 63-66.

Breslav, G. (1994, June-July). Vygotsky's concept of the "Social situation of development": Current perspective. Paper presented at the 13th Biennial Meetings of ISSBD, Amsterdam.

Breslav, G. M. (2004). Psikhologiya emotsii [The psychology of emotions]. Moscow: Smysl/Akademiya.

Breslav, G. (2008). Lyubov' i revnost': Druz'ya ili vragi? [Love and jealousy: friends or foes?] CommunicatoR, 1/2, 178-181.

Breslav, G. M. (2010). Osnovy psikhologicheskogo issledovaniya [The fundamentals of the psychological research]. Moscow: Smysl-Akademiya.

Breslav, G. (2013). Elaboration of Frequency Index of Sexual Satisfaction (FISS) in marital relationships assessment. Psychology. Journal of the Higher School of Economics, 10(1), 25-36.

Breslav, G. M. (2016). Psikhologiya emotsii [The psychology of emotions] (4nd ed.). Moscow: Smysl.

Breslavs, G. (1982). Cik soḷ no milestỉbas līdz naidam? Skola un G̦imene, 2.

Breslavs, G. (2009, August). Are adults' love and hate more advanced? The paper presented at the XIVth European Conference on Developmental Psychology, Vilnius.

Breslavs, G. (2013). Moral emotions, conscience and cognitive dissonance. Psychology in Russia: State of the Art, 6(4), 65-72. doi:10.11621/pir.2013.0405

Breslavs, G. (2014). Psychological security of two generations in Latvia.Journal of the Siberian Federal University. Humanities and Social Sciences, 7(12), 2191-2204.

Buunk, B. P., \& Van Yperen, N. W. (1991). Referential comparisons, relational comparisons and exchange orientation: their relation to marital satisfaction. Personality and Social Psychology Bulletin, $17,710-718$.

Carver, C. S., Lawrence, J. W., \& Scheier, M. F. (1996). A control-process perspective on the origins of affect. In L. L. Martin \& A. Tesser (Eds.), Striving and feeling: Interaction among goals, affect, and self-regulation (pp. 11-52). Mahwah, NJ: LEA Publishers.

Cook, D. R. (1996). Empirical studies of shame and guilt: The Internalized Shame Scale. In D. L. Nathanson (Ed.), Knowing feeling: Affect, script and psychotherapy (pp. 132-165). New York: Norton.

Cryder, C. E., Springer, S., \& Morewedge, C. K. (2012). Guilty feelings, targeted actions. Personality and Social Psychology Bulletin, 38, 607-618. doi:10.1177/0146167211435796

Cusack, C. E., Hughes, J. L., \& Cook, R. E. (2012). Components of love and relationship satisfaction: Lesbians and heterosexual women. Psi Chi Journal of Psychological Research, 17(4), 171-179.

Day, M. V., \& Bobocel, D. R. (2013). The weight of a guilty conscience: Subjective body weight as an embodiment of guilt. PLoS ONE, 8(7), 1-7. doi:10.1371/journal.pone.0069546

Duffy, E. (1941/1969). An explanation of "emotional" phenomena without the use of the concept "emotion”. In M. Arnold (Ed.), The nature of emotion (pp. 129-140). Harmondsworth: Penguin Books.

Dugosh, J. W. (2000). On predicting relationship satisfaction from jealousy: the moderating effects of love. Current Research in Social Psychology, 5(17), 254-263.

Felmlee, D. (1995). Fatal attractions: Affection and disaffection in intimate relationship. Journal of Social and Personal Relationships, 12, 295-311.

Ferguson, T. J., Stegge, H., \& Damhuis, I. (1991). Children understanding of guilt and shame. Child Development, 62, 827-839. 
Fourie, M. M., Thomas, K. G. F., Amodio, D. M., Warton, C. M. R., \& Meintjes, E. M. (2014). Neural correlates of experienced moral emotion: An fMRI investigation of emotion in response to prejudice feedback. Social Neuroscience, 9(2), 203-218. doi:10.1080/17470919.2013.878750

Frijda, N. H. (1970). Emotion and recognition of emotion. In M. Arnold (Ed.), Feelings and emotions (pp. 241-250). New York: Academic Press.

Furman, W., \& Wehner, E.A. (1997). Adolescent romantic relationships: A developmental perspective. In S. Shulman \& A. Collins (Eds.), Romantic relationships in adolescence: New Directions for Child Development (pp. 21-36). San Francisco: Jossey-Bass.

Gausel, N., Leach, C. W., Vignoles, V. L., \& Brown, R. (2012). Defend or repair? Explaining responses to ingroup moral failure by disentangling feelings of shame, rejection, and inferiority. Journal of Personality and Social Psychology, 102, 941-960. Retrieved from http://dx.doi.org/10.1037/ a0027233

Gilbert, P. \& Miles, J. (Eds.). (2002). Body shame: Conceptualisation, research and treatment. Hove: Brunner-Routledge.

Hatfield, E., \& Sprecher, S. (1986). Measuring passionate love in intimate relations. Journal of Adolescence, 9, 383-410.

Hazan, C., \& Shaver, P. (1997). Romantic love conceptualised as an attachment process. In M. Hewstone, A. S. Manstead, \& Stroebe, W. (Eds.), The Blackwell reader in social psychology (pp. 377-406). Oxford: Blackwell.

Hendrick, C., \& Hendrick, S. (1986). A theory and method of Love. Journal of Personality and Social Psychology, 50, 392-402.

Iyer, A., Schmader, T., \& Lickel, B. (2007). Why individuals protest the perceived transgressions of their country: The role of anger, shame, and guilt. Personality and Social Psychology Bulletin, 33, 572-587. Retrieved from http://dx.doi.org/10.1177/0146167206297402

Izard, C. E. (1971). The face of emotion. New York: Appleton-Century-Crofts.

Kagan, J., Keasley, R. B., \& Zeiazo, P. R. (1980). Infancy: Its place in human development. Cambridge, MA: Harvard University Press.

Knapp, M. L., \& Vangelisti, A. (1992). Interpersonal communication and human relationships (2nd ed.). Boston: Allyn \& Bacon.

Kouchaki, M., Gino, F., \& Jami, A. (2014). The burden of guilt: Heavy backpacks, light snacks, and enhanced morality. Journal of Experimental Psychology: General, 143(1), 414-424. doi:10.1037/a0031769

Lazarus, R. S., Averill, J. R., \& Opton, E. M. (1970). Toward a cognitive theory of emotions. In M. Arnold (Ed.), Feelings and emotions (pp. 207-232). New York: Academic Press.

Leontiev, A. N. (1971). Potrebnosti, motivy i emotsii [Needs, motives and emotions]. Moscow: Moscow University Press.

Lewin, K. (1936). Principles of topological psychology. New York: McGraw-Hill.

Lindsay-Hartz, J., De Rivera, J., \& Mascolo, M. F. (1995). Differentiating guilt and shame and their effect on motivation. In J. P. Tangney \& K. Fisher (Eds.), Self-conscious emotions: The psychology of shame guilt, embarrassment, and pride (pp. 274-300). New York: Guilford Press.

Menesini, E., \& Camodeca, M. (2008). Shame and guilt as behaviour regulators: Relationships with bullying, victimization and prosocial behaviour. British Journal of Developmental Psychology, 26, 183-196.

Mesquita, B. (2001). Emotions in collectivist and individualist contexts. Journal of Personality and Social Psychology, 80(1), 68-74. 
Murray, S. L., Holmes, J. G., \& Griffin, D. W. (1996). The benefits of positive illusions: Idealization and the construction of satisfaction in close relationships. Journal of Personality and Social Psychology, 70, 79-98.

Nelissen, R. M. A. (2014). Relational utility as a moderator of guilt in Social Interactions. Journal of Personality EF Social Psychology, 106(2), 257-271. doi:10.1037/a0034711

Oatley, K., \& Johnson-Laird, P. N. (1996). The communicative theory of emotions: Empirical tests, mental models, and implications for social interaction. In L. L. Martin \& A. Tesser (Eds.), Striving and feeling: Interaction among goals, affect, and self-regulation (pp. 363-393). Mahwah, NJ: LEA Publishers.

Olthof, T. (2012). Anticipated feelings of guilt and shame as predictors of early adolescents' antisocial and prosocial interpersonal behaviour. European Journal of Developmental Psychology, 9(3), 371-88.

Parkinson, B., \& Illingworth, S. (2009). Guilt in response to blame from others. Cognition and Emotion, 23(8), 1589-1614.

Piff, P. K., Martinez, A. G., \& Keltner, D. (2012). Me against we: Ingroup transgression, collective shame, and ingroup directed hostility. Cognition and Emotion, 46, 634-649. Retrieved from http://dx.doi.org/10.1080/02699931.2011.595394.

Plutchik, R. (1970). Emotions, evolution, and adaptive processes. In M. Arnold (Ed.), Feelings and emotions (pp. 3-24). New York: Academic Press.

Poerio, G. L., Totterdell, P., Emerson, L.-M., \& Miles, E. (2015). Love is the triumph of the imagination: Daydreams about significant others are associated with increased happiness, love and connection. Consciousness and Cognition, 33, 135-144. doi:10.1016/j.concog.2014.12.011

Retzinger, S. M. (1991). Violent emotions: Shame and rage in marital quarrels. Newbury Park, CA: Sage.

Robak, R. W., \& Weitzman, S. P. (1998). The nature of grief: Loss of love relationships in young adulthood. Journal of Personal and Interpersonal Loss, 3(2), 205-216.

Rubin, Z. (1970). Measurement of romantic love. Journal of Personality and Social Psychology, 16, 265-273.

Rusbult, C. E. (1983). A longitudinal test of the investment model: The development (and deterioration) of satisfaction and commitment in heterosexual involvements. Journal of Personality and Social Psychology, 45, 101-117.

Rusbult, C. E. \& Buunk, A. P. (1993). Commitment processes in close relationships: an interdependence analysis. Journal of Social and Personal Relationships, 10, 175-204.

Schachter, S., \& Singer, J. E. (1962). Cognitive, social, and physiological determinants of emotional state. Psychological Review, 69, 379-399.

Scherer, K. R. (1984). On the nature and function of emotion: A component process approach. In K. R. Scherer \& P. Ekman (Eds.), Approaches to emotion (pp. 293-317). Hillsdale, NJ: Erlbaum.

Scherer, K. (1996). Emotion. In M. Hewstone, W. Stroebe, \& G. M. Stephenson (Eds.), Introduction to social psychology (pp. 279-315). Oxford: Blackwell Publ.

Sternberg, R. J. (1994). Love is a story. The General Psychologist, 30(1), 1-11.

Sternberg, R. J. (1997). Construct validation of a triangular love scale. European Journal of Social Psychology, 27(3), 313-335.

Sternberg, R., Hojjat, M., \& Barnes, M. (2001). Empirical tests of aspects of a Theory of love as a story. European Journal of Personality, 15, 199-218.

Swensen, C., \& Gilner, F. (1964). Factor analysis of self-report statement on love relationships.Journal of Individual Psychology, 20, 186-188. 
Tangney, J. P. (1995). Shame and guilt in interpersonal relationships. In J. P. Tangney \& K.W. Fischer (Eds.), Self-conscious emotions: Shame, guilt, embarrassment, and pride (pp. 114-139). New York: Guilford Press.

Tangney, J. P., \& Fisher, K. W. (Eds.). (1995). Self-conscious emotions: The psychology of shame guilt, embarrassment, and pride. New York: Guilford Press.

Tangney, J. P., Wagner, P., Fletcher, C., \& Gramzow, R. (1992). Shamed into anger? The relation of shame and guilt to anger and self-reported aggression. Journal of Personality and Social Psychology, 62, 669-675.

Tesser, A., \& Paulhus, D. L. (1976). Toward a causal model of love. Journal of Personality and Social Psychology, 34, 1095-1100.

Tomkins, S. S. (1962). Affect, imagery, and consciousness (Vol. 1: The positive affects). New York: Springer.

Vilyunas, V. K. (1976). Psikhologiya emotsional'nykh yavlenii [The psychology of emotional phenomena]. Moscow: Moscow University Press.

Whitton, S. W., Rusbult, C. E., \& Wieselquist, J. (1999). Close partner as sculptor of the ideal self: Behavioral affirmation and the Michelangelo phenomenon. Journal of Personality and Social Psychology, 77(2), 294-324. 